\title{
Weight loss programmes using low carbohydrate diets to control the cardiovascular risk in adolescents (Review)
}

\author{
ROXANA ADRIANA STOICA ${ }^{1}$ CAMELIA CRISTINA DIACONU ${ }^{2}$, MANFREDI RIZZO $^{3,4}$, PETER P. TOTH ${ }^{5}$, \\ SIMONA DIANA STEFAN ${ }^{1}$, CRISTIAN SERAFINCEANU ${ }^{1}$, DRAGANA NIKOLIC ${ }^{6,7}$, \\ CATALINA POIANA $^{8}$, CONSTANTIN IONESCU-TIRGOVISTE ${ }^{1,9}$ and ANCA PANTEA-STOIAN ${ }^{1}$ \\ ${ }^{1}$ Department of Diabetes, Nutrition and Metabolic Diseases, 'Carol Davila' University of Medicine and Pharmacy, \\ 020475 Bucharest; ${ }^{2}$ Department of Internal Medicine, 'Carol Davila' University of Medicine and Pharmacy, \\ 014461 Bucharest, Romania; ${ }^{3}$ Biomedical Department of Internal Medicine and Medical Specialities, \\ University of Palermo, I-90139 Palermo, Italy; ${ }^{4}$ Division of Endocrinology, Diabetes and Metabolism, \\ Medical University of South Carolina, Charleston, SC 29425; ${ }^{5}$ Ciccarone' Center for The Prevention of \\ Cardiovascular Disease, Johns Hopkins University School of Medicine, Baltimore, MD 21205-2196, USA; \\ ${ }^{6}$ Department of Health Promotion, Mother and Child Care, Internal Medicine and Medical Specialties, \\ University of Palermo, I-90127 Palermo; ${ }^{7}$ Euro-Mediterranean Institute of Science and Technology (IEMEST), \\ I-90139 Palermo, Italy; ${ }^{8}$ Department of Endocrinology, 'Carol Davila' University of Medicine and Pharmacy, \\ 011863 Bucharest; ${ }^{9}$ Department of Medical Sciences, Romanian Academy, 050711 Bucharest, Romania
}

Received September 2, 2020; Accepted October 2, 2020

DOI: $10.3892 /$ etm.2020.9522

\begin{abstract}
Cardiovascular risk (CVR) is a broad term that includes traditional factors like hypertension, hyper lipidemia, abdominal obesity, hyperinsulinemia or overt type 2 diabetes mellitus (T2DM), and emerging ones such as hypothyroidism or inflammatory diseases. In epidemiologic studies, all of these factors are associated with atherogenesis and have complex interactions between them. They have in common an increased prevalence in the general population beginning in childhood, and are correlated with endothelial damage as demonstrated by echocardiographic modifications of the left ventricle or carotid intima-media thickness. Adolescence is a transition period where behavioural eating patterns develop and have a major impact on cardiovascular risk. To address these patterns, weight-loss programmes under medical supervision for overweight and obese adolescents are developed. It was observed that those who control the quality and quantity of their carbohydrates, by consuming more fruits and vegetables, associated with increased physical activity reduce their CVR. Some limited studies have shown that low carbohydrate diet (LCD) is safe and effective, but one should take into consideration the limited duration and
\end{abstract}

Correspondence to: Ms. Simona Diana Stefan, Department of Diabetes, Nutrition and Metabolic Diseases, 'Carol Davila' University of Medicine and Pharmacy, 5-7 Ion Movila Street, 020475 Bucharest, Romania

E-mail: simona_ds2002@yahoo.com

Key words: low carbohydrate diet, nutritional intervention, cardiovascular risk, adolescent, obesity the structure of the LCD. If there is a proper adherence to this type of nutritional intervention, it results in weight loss, improvement in insulin resistance, lipid profile and subclinical hypothyroidism reversal. We reviewed the literature starting from 2009 by searching all the observational, randomised clinical trials and meta-analyses on MEDLINE and SCOPUS databases regarding obesity and related metabolic diseases (dyslipidemia, type 2 diabetes, hypertension, hypothyroidism, LCD) in adolescents and synthesized the nutritional interventions for this population that could decrease CVR.

\section{Contents}

1. Cardiovascular risk components in adolescents

2. Adolescent dietary patterns between 2000-2019

3. Low carbohydrate diet for controlling cardiovascular risk factors

4. Conclusions

\section{Cardiovascular risk components in adolescents}

Environmental, behavioural, and genetic factors potentiate the risk of early childhood (age 1-9 years) and adolescent (age 10-19 years) obesity, three-quarters of this population suffering the consequences in adulthood (1). According to the World Health Organization (WHO) Commission on Ending Childhood Obesity, the prevalence of obesity in this population is rising globally, especially in low and middle-income countries (2), reaching an alarming percent of $21 \%$ even in well-developed countries like USA (3). The objective of WHO is to limit the expansion and the burden of this disease by 2025 (4). 
The definition of childhood obesity is a body mass index (BMI) above two standard deviations (SD), meaning the 98th percentile on growth charts (National Institute for Health and Care Excellence guidelines) or above the 95th percentile (USA American Academy of Pediatrics guidelines). A body mass index above 3.5 SD is considered extreme obesity and should be referred for speciality care due to the increased likelihood of comorbidities (5).

Genetic predisposition cannot by itself explain the rapid evolution during the last 20 years (4). The obesogenic environment consisting of excessive calorie diets, a sedentary lifestyle, the globalised food market, and economic interests are factors that increase the incidence of this disease $(4,5)$. Obesity has a short-term impact by amplification of the inflammatory process and the pathologies that derive from this (asthma, non-alcoholic fatty liver disease, muscular and skeletal disease), and a long-term impact on cardiovascular risk (CVR) $(4,6)$.

High triglycerides and a low high-density lipoprotein cholesterol (HDL-C) level (atherogenic dyslipidemia) are other classic CV factors. In order to include them in the metabolic syndrome definition for this population, some authors have selected clear numerical values $(7,8)$, or percentiles, especially for young children (9). Lipid profile variations are linked to inflammation, thus raising CVR. In girls, interleukin-6 (IL-6) is associated with differences in the HDL-C/triglyceride (TG) ratio, and in boys, interleukin-1 $\beta$ (IL-1 $\beta$ ) and tumor necrosis factor- $\alpha(\mathrm{TNF}-\alpha)$ also correlate with this ratio (10).

Hypertension (HTN) in adolescents and youth has become a public health problem because it is a predictor of coronary artery disease (CAD) and end-stage renal disease in adults (11). HTN is defined as persistent blood pressure (BP) above the 95th percentile of BP in healthy children. Its prevalence depends on age, with the highest peak at puberty $7.89 \%$ (with a 95\% confidence interval-CI between 5.75 and $10.75 \%$ ), and methods used for measuring (aneroid, mercury or oscillometric sphygmomanometer) (12).

The study of hypertension in younger populations is essential because arteriosclerosis, or arterial stiffness, is the first step in vascular ageing and later progression to atherosclerosis. The methods used for measuring arterial stiffness, and thus endothelial dysfunction, are pulse wave velocity (PWV) and Cardio-Ankle Brachial Index (CAVI). Although hypertension induces endothelial dysfunction and correlates with increased PWV in extensive cohort adult studies, the direct effect of HTN on arterial stiffness in a study which included 29 obese children could not be clearly quantified (13).

Hypothyroidism is a disputed cardiovascular risk factor. Thyroid hormone T3 has specific protein transporters on cardiac myocytes and once inside the cell exerts genomic and non-genomic effects (14). At the vascular level, T3 deficiency is associated with increased vascular resistance and arterial stiffness (15), as well as hemodynamic changes in the kidney, leading to hypertension. Hypothyroidism is also associated with obesity, so it has an indirect effect on CVR (16).

In Indian adolescents, one cross-sectional study found elements of atherogenic dyslipidemia and insulin resistance in subclinical hypothyroidism (17). On the other hand, in an Asian population, subclinical hypothyroidism was not associated with the metabolic syndrome, although a trend toward blood pressure elevation was observed (18). The odds ratio of having subclinical hypothyroidism in a cross-sectional study with 3,006 Danish children was 1.8 when being overweight/obese $(\mathrm{P}=0.0007)$, or presenting with a waist to hip ratio of greater than $0.5(\mathrm{P}=0.0003)(19)$. This connection between a higher thyroid stimulating hormone (TSH) and a higher BMI with an indirect effect on CVR was observed in a small cohort of 46 American children with primary hypothyroidism on hormone replacement therapy; the correlation coefficient was small $(r=0.274, P=0.001)(20)$.

\section{Adolescent dietary patterns between 2000-2019}

Assessing dietary patterns is difficult in daily practice. The most used methods are written journals, smartphone applications, and 24-48 h recall. All the methods are subjective because obese children, and adolescents have a tendency to under-report food intake (21). We took into consideration demography, gender, education and race/ethnicity as the most probable factors determining nourishment quantity and quality in adolescent population.

i) Demography. There are heterogeneous patterns of obesity distribution related to food accessibility, traditions and economy. In countries with a tradition for a healthy eating lifestyle like Greece, the overweight problem appears in children who consumed more processed snacks like milk chocolate $(1.87 \pm 0.3$ vs. $0.5 \pm 0.8)$, cheese pie $(2.61 \pm 1.85$ vs. $1.22 \pm 0.81)$, potato chips $(2.03 \pm 0.78$ vs. $0.93 \pm 0.80)$, or added sugar (14.57 \pm 8.25 tablespoons vs. 9.95 \pm 6.85$)$ (21). A cross-sectional study in Ecuador showed that adolescents who consume fewer fibers, vegetables, fruits and fish or more processed food than dietary reference intake (DRI) had increased CVR (22). In other words, the adolescents who adopt the Western-like diet to the detriment of Mediterranean-like diet, tend to become obese.

The Healthy Lifestyle in Europe by Nutrition Intervention in Adolescence (HELENA) study observed that breakfast consumers have a lower percentage of body fat and higher cardiovascular fitness $[\mathrm{OR}=0.56$ with $95 \% \mathrm{CI}(0.32,0.98)]$, compared to breakfast-skippers $[\mathrm{OR}=0.33$ with $95 \% \mathrm{CI}$ $(0.18 ; 0.59)]$. The amount of fruits, legumes and milk is at least twice lower than recommended in adolescents. Sugar added beverages, juices and milk sum up to provide the highest percentage of energy from daily requirements and are associated with an increased value of homeostatic model assessement of insulin resistance (HOMA IR) index. There was also an extensive biochemical evaluation, which identify the most common vitamin deficiencies associated with these patterns: $\beta$-carotene $(25 \%)$, folate $(15 \%)$, vitamin D $(15 \%)$, pyridoxal (5\%), and vitamin E (5\%) (23).

The USA has invested considerable efforts in improving dietary quality. In a review published in 2019, average vegetable and fruit consumption was less the 5 portions per day and little is known about legume or salt intake (24). Researchers and government institutions developed indices such as the Healthy Eating Index 2010 and programmes like the National School Lunch Program (NSLP) and the School Breakfast Program (SBP) and achieved a reduction in low-quality food (25).

Increasing trends in non-healthy cardiovascular behaviours are observed in Chinese children. Dong et al used a 7 metric score to define ideal cardiovascular health that includes 
smoking behaviour, body mass index, physical activity, diet and biologic factors (total cholesterol, blood pressure, and glucose). The ideal $\mathrm{CV}$ health (ICVH) worsened over a 10 year period, with $19.5 \%$ of boys and $22.0 \%$ of girls having ICVH in 2004, and $9.8 \%$ of boys and $16.0 \%$ of girls in 2014 (26).

Urban children are more exposed to living in high-density areas selling high-calorie fast food and junk food, also named 'food swamp,' which positively correlates with obesity. In some disadvantaged areas in Baltimore, United States, there is a lack of fresh fruit and legume stores ('food desert'), making fast-food eating more within reach (27). Other populations have disparate patterns: In Ecuador, urban adolescents have a 'rice-rich, non-animal fat pattern' linked to elevated blood glucose, and rural adolescents have a 'wheat-dense, animal-fat pattern' related to dyslipidemia (22).

ii) Gender. The distribution of CVR factors differs between sexes and is influenced by puberty stages. Obese males at puberty stage 4-5 (Tanner) have higher systolic blood pressure. Puberty progression is associated with higher insulin resistance in females and dyslipidemia in advancing from stage 2 to 3 (28). Besides these physiological factors, the response to external stimuli seems to act differently at the psychological level. For example, adolescent girls are more prone to eat unhealthy snacks if they live in under-resourced communities. Girls living in food swamps consumed more snacks or desserts ( 3.7 vs. 3.1 servings/day $\mathrm{P}=0.003$ ) than those living in wealthy neighbourhoods (27).

iii) Economic status and education. CVR is influenced by childhood or adolescent adversity that will result in latter adult health behaviour, including eating behaviours, as well as educational and financial stress. A lower socioeconomic status independently increases CVR risk as demonstrated by the National Longitudinal Study of Adolescent to Adult Health which has followed 14,493 US adolescents from a mean age of 15.9 years through early adulthood (mean age 28.9 years) (29).

iv) Race and ethnicity. In their study cohort, de Ferranti et al showed that Mexican-Americans and non-Hispanic whites had the highest prevalence of metabolic syndrome $12.9 \%$, 95\% CI [10.4\%; $15.4 \%]$ and $10.9 \%, 95 \%$ CI $[8.4 \% ; 13.4 \%]$, when compared to non-Hispanic blacks $2.5 \%, 95 \%$ CI [1.3\%; $3.7 \%$ ] (8). The obesity prevalence is higher in ethnic subgroups like Hispanic adolescents $(\mathrm{RR}=1.08, \mathrm{P}<0.0001)$ vs. Caucasians $(\mathrm{RR}=0.95, \mathrm{P}<0.0001)$ (3). In Europe, ethnic minorities such as black African children or Rroma tend to be more obese than white children (30).

\section{Low carbohydrate diet for controlling cardiovascular risk factors}

Obesity. The WHO published a series of recommendations to implement comprehensive programmes in order to promote healthy eating, physical activity, and non-sedentary behaviour. Also, it encourages preconception and antenatal education, healthy school environments, and family-based lifestyle interventions (2).

One can start LCD after obtaining the caloric requirement of the patient by applying the carbohydrate restriction in agreement with patient preferences, cultural and family traditions, social and economic status. The reduction of soft drinks, instant meals and sweets is the first measure, because it is associated with a decrease in BMI, abdominal circumference (a marker of insulin resistance) and a better life quality (31). Observational and interventional studies have discrepant results regarding the best method for weight control (32).

In general, healthy carbohydrate intake is estimated between $45-60 \%$ of the total daily caloric requirement. Carbohydrate restriction (less than $130 \mathrm{~g} /$ day) can be classified as low-moderate carbohydrate diet (26-45\%) and very-low carbohydrate diet (10-25\%) (33). American Diabetes Association (ADA) guidelines do not recommend the use of a low-carbohydrate diet in pregnancy or children. Adolescents are the frontier between children and adults and could benefit from an early carbohydrate restriction because a high intake is associated with a progression of atherosclerosis (34).

Thus, most of the studies implementing this diet were performed in adult populations. Besides the disadvantage of scattered data in the youth population, comparing the results of studies is challenging, because the nutrient ratio and carbohydrate restriction are heterogeneous (35-37). Also, appreciating the carbohydrate content is different, some studies do not specify if they consider the general term that includes sugar, starch and fiber or if they treat them separately (6).

Demol et al (38) compared a low carbohydrate-low-fat diet (LCLF) with low carbohydrate-high-fat diet (LCHF) and high carbohydrate-low fat diet (HCLF) with 1,200-1,500 kcal/day in 55 adolescents between 12 and 16 years in a 12 -week intervention trial. There were no significant differences regarding weight loss between diets. All diets seem to be safe with no modification on renal or hepatic function, and no increase in anaemia, vitamin deficiencies or electrolyte disturbances. Adolescents in all 3 groups had an increase in the fat percentage at 52-week follow-up that was lower than the initial values.

Regarding carbohydrate metabolism, there was a significant decrease in baseline insulin and HOMA levels that were reported only in the groups with low-carbohydrate diet, but not in the high-carbohydrate diet group, both by the end of the intervention ( $\mathrm{LCLF} t=2.49, \mathrm{P}=0.026$ for insulin and $\mathrm{t}=2.81$, $\mathrm{P}=0.014$ for HOMA, LCHF $\mathrm{t}=4.26, \mathrm{P}=0.002$ for insulin and $\mathrm{t}=4.59, \mathrm{P}<0.001$ for HOMA) and by the end of the follow-up period. Also, total cholesterol, LDL-cholesterol, HDL cholesterol and TG levels decreased significantly in all groups; CRP did not change significantly (38).

Diets with an average carbohydrate intake but with a higher protein content were not superior in comparison with standard diet in decreasing body weight, changing body composition or appetite (hunger motivation). The percent of protein was $22.5 \%$ of total calories and could be insufficient for hunger suppression, given the fact that some children eat up to $30 \%$ protein in their daily diet (39). This result is reproducible and was observed in summer weight loss camps for obese children with at least 5 weeks of duration intervention $(40,41)$. Thus, diets with a moderate low carbohydrate intake $(35 \%)$ and a moderate-high protein (30\%) and normal fat (35\%) percent could improve insulin resistance and decrease sugar-craving that was described after sugar-sweetened beverages were prohibited (42). The time of initiating a diet is also important 
because adolescents are emotionally vulnerable, and restrictive diets could degenerate into eating disorders. The majority of studies have a mean age of 14 years $(35,37,38)$.

Although few studies have attached an appendix with the structure of the diet (42), in a very low carbohydrate diet (VLCD) the only sources of these macronutrients are green vegetables high in soluble fiber and with a low glycemic index (for example, broccoli, salad, green beans, mushrooms), fruits (avocado), or insoluble fiber-nuts and seeds (almond, walnuts, macadamia). In LCD, a nutritionist can add weighed quantities of whole grains, pasta and rice, potatoes, lentils, corn or fruits like citrus, berries, green apples that do not exceed the $40 \%$ of caloric requirement. Sweetened beverages, alcohol, high carbohydrate sauces, or white flour containing products such as white bread, sweets and cakes, and pastries are restricted.

The duration of intervention should be carefully selected. In adults, VLCD (<20 g/day) was designed with a shorter period than a moderate low carbohydrate diet, probably due to lower adherence (43). Thus, VLCD in adolescents are not recommended for weight loss.

Hyperinsulinemia and type 2 diabetes. The objective of nutritional intervention in adolescents with type 2 diabetes is to achieve an equilibrium between food intake and energy expenditure in order to assure sufficient energy for growth without inappropriate weight gain. Developing lifelong eating habits is encouraged rather than short-term restrictive diets (44).

International Society for Pediatric and Adolescent Diabetes (ISPAD) guidelines recommend at least $45 \%$ carbohydrates in children and adolescents, but adjustments can be made down to $40 \%$ if the protein intake is raised $(34,44)$. VLCD is not advised because it can lead to calcium, magnesium, iron and gastrointestinal disturbances (vomiting, diarrhea, or constipation) that could slow down normal growth as was observed when implementing the ketogenic diet in children with various types of seizure disorders (45). The adolescents and their families should be taught how to reduce portions, how to make healthy choices like foods with a lower glycemic index and to avoid empty calories (44). Moderate low carbohydrate diets can prove beneficial for controlling T2DM and reducing CVR. Adolescents that were on two low carbohydrate diets had a lower insulin level and HOMA-IR index compared with those on high carbohydrate low-fat diets (38).

Dyslipidemia. A low-carbohydrate diet is associated with a decrease in total cholesterol, LDL cholesterol and TG in a study with 55 obese adolescents, but the authors do not specify the exact values (38). Sondike et al (35) showed in their research on 22 adolescents that total cholesterol decreased by $37 \pm 18 \mathrm{mg} / \mathrm{dl}$, TG by $48.3 \pm 29.0 \mathrm{mg} / \mathrm{dl}$, and non-HDL cholesterol by $26.0 \pm 22.3 \mathrm{mg} / \mathrm{dl}$, all statistically significant from baseline (46). Reducing total fat content to $25-35 \%$ of energy, saturated fat content to $<7 \%$, and increasing fiber to $14 \mathrm{~g}$ per $1,000 \mathrm{kcal}$ together with increased physical activity are the most important measures.

Hypertension. In one randomised study (47), adolescents that followed a diet based on fruits, vegetables and low fats (DASH) had a lower SBP $\mathrm{z}$ score from baseline to post-treatment $(\mathrm{P}<0.01)$ and a more significant decrease in SBP $\mathrm{z}$ scores from baseline through a 3-month follow-up $(\mathrm{P}=0.07)$. In the Dietary Approaches to Stop Hypertension (DASH) diet group $(n=24)$ the mean SBP was $131.3 \pm 8.9 \mathrm{mmHg}$ at baseline and $120.9 \pm 10.4 \mathrm{mmHg}$ after the intervention, which was maintained for 3 months. Thirty-three children treated with a low carbohydrate, high protein (LCHP) diet for a mean period of 29 days had a lower SBP at the end of programme compared to those on a standard diet $(113 \pm 9$ vs. $108 \pm 8 \mathrm{mmHg}$ on LCHP, and $114 \pm 9$ vs. $111 \pm 10.0 \mathrm{mmHg}$, on standard, $\mathrm{P}=0.001$ ), and a lower DBP $(64 \pm 8$ vs. $59 \pm 6 \mathrm{mmHg}$ on LCHP, and $67 \pm 10$ vs. $62 \pm 7 \mathrm{mmHg}$ on standard, $\mathrm{P}=0.001$ ) (37). The differences in the weight loss between groups could affect the result, and this may be the reason why not all authors included a BP evaluation $(35,38)$.

Inflammatory factors, namely TNF- $\alpha$, IL-1 $\beta$, IL-6, and C-reactive protein decrease in adults following a LCD, but the evidence is lacking in adolescents (6).

Hypothyroidism. There are no specific nutritional guidelines for this population. Modifications of thyroid function are reversible after overweight and obese young persons lose weight (48). The effects of hypothyroidism in the long-term are not known and could affect the CVR, directly or through secondary dyslipidemia.

\section{Conclusions}

Current dietary patterns in adolescents are heterogeneous and reflect the evolution of modern economies with reduced fruit, vegetables and unsaturated fat consumption and an abundance of empty-calorie containing food. Thus, CVR is increasing generation by generation. Low carbohydrate diets under medical supervision (weekly or at least a monthly evaluation) starting at a mean age of 14 years was proven to be safe and efficacious on one or more components of the metabolic syndrome and could represent a solution for decreasing CVR.

The preferred sources of carbohydrates for LCD in adolescents are vegetables and fruits rich in soluble fibers with a low glycemic index, and small amounts of whole grains, pasta and rice, potatoes, lentils, or corn.

\section{Acknowledgements}

Not applicable.

\section{Funding}

No funding was received.

\section{Availability of data and materials}

Not applicable.

\section{Authors' contributions}

APS, CS and CIT contributed in the conseption of the study. RAS and SDS participated in the collection of the data and performed the literature search. CCD, MR, PPT, DN and CP revised the study for important intellectual content. All authors were involved in writing the manuscript. All authors read and approved the final manuscript. 


\section{Ethics approval and consent to participate}

Not applicable.

\section{Patient consent for publication}

Not applicable.

\section{Publication of clinical datasets}

Not applicable.

\section{Competing interests}

The authors declare that they have no competing interests.

\section{References}

1. Kohut T, Robbins $\mathbf{J}$ and Panganiban J: Update on childhood/adolescent obesity and its sequela. Curr Opin Pediatr 31: 645-653, 2019.

2. World Health Organization. (2016). Report of the commission on ending childhood obesity. https://apps.who.int/iris/bitstream/ handle/10665/204176/9789241510066_eng.pdf?sequence $=1$. Accessed October 24, 2019.

3. Humayon S, Altieri MS, Yang J, Nie L, Spaniolas K and Pryor AD Recent trends of bariatric surgery in adolescent population in the state of New York. Surg Obes Relat Dis 15: 1388-1393, 2019.

4. Di Cesare M, Sorić M, Bovet P, Miranda JJ, Bhutta Z, Stevens GA Laxmaiah A, Kengne AP and Bentham J: The epidemiological burden of obesity in childhood: A worldwide epidemic requiring urgent action. BMC Med 17: 212, 2019.

5. Viner RM, White B, Barrett T, Candy DC, Gibson P, Gregory JW Matyka K, Ong K, Roche E, Rudolf MC, et al: Assessment of childhood obesity in secondary care: OSCA consensus statement. Arch Dis Child Educ Pract Ed 97: 98-105, 2012.

6. Stanczak P and Weikel KA: Reducing cardiovascular disease risk in youth with type 2 diabetes through dietary carbohydrate restriction: Clinical and molecular perspectives. EC Nutr 9 263-298, 2017.

7. Nielsen TRH, Lausten-Thomsen U, Fonvig CE, Bøjsøe C, Pedersen L, Bratholm PS, Hansen T, Pedersen O and Holm JC: Dyslipidemia and reference values for fasting plasma lipid concentrations in Danish/North-European white children and adolescents. BMC Pediatr 17: 116, 2017.

8. de Ferranti SD, Gauvreau K, Ludwig DS, Neufeld EJ, Newburger JW and Rifai N: Prevalence of the metabolic syndrome in American adolescents: Findings from the Third National Health and Nutrition Examination Survey. Circulation 110 2494-2497, 2004.

9. Ahrens W, Moreno LA, Mårild S, MolnárD, Siani A,De Henauw S, Böhmann J, Günther K, Hadjigeorgiou C, Iacoviello L, et al: Metabolic syndrome in young children: Definitions and results of the IDEFICS study. Int J Obes (Lond) 38 (Suppl 2): S4-S14, 2014

10. Teixeira Silva C, Cândido APC, Pala D, Oliveira Barbosa P, Machado-Coelho GLL, Pereira de Oliveira FL, Pinheiro Volp AC and Nascimento de Freitas R: Clustered cardiovascular risk factors are associated with inflammatory markers in adolescents. Ann Nutr Metab 70: 259-267, 2017.

11. Lurbe E, Agabiti-Rosei E, Cruickshank JK, Dominiczak A Erdine S, Hirth A, Invitti C, Litwin M, Mancia G, Pall D, et al: 2016 European society of hypertension guidelines for the management of high blood pressure in children and adolescents. J Hypertens 34: 1887-1920, 2016

12. Song P, Zhang Y, Yu J, Zha M, Zhu Y, Rahimi K and Rudan I: Global prevalence of hypertension in children: A systematic review and meta-analysis. JAMA Pediatr 173: 1-10, 2019.

13. Czippelova B, Turianikova Z, Krohova J, Wiszt R, Lazarova Z, Pozorciakova K, Ciljakova M and Javorka M: Arterial stiffness and endothelial function in young obese patients-vascular resistance matters. J Atheroscler Thromb 26: 1015-1025, 2019.

14. Bassett JH, Harvey CB and Williams GR: Mechanisms of thyroid hormone receptor-specific nuclear and extra nuclear actions. Mol Cell Endocrinol 213: 1-11, 2003.
15. Dagre AG, Lekakis JP, Papaioannou TG, Papamichael CM, Koutras DA, Stamatelopoulos SF and Alevizaki M: Arterial stiffness is increased in subjects with hypothyroidism. Int J Cardiol 103: 1-6, 2005.

16. Chopra S, Cherian D and Jacob JJ: The thyroid hormone, parathyroid hormone and vitamin D associated hypertension. Indian J Endocrinol Metab 15 (Suppl 4): S354-S360, 2011.

17. Yadav Y, Saikia UK, Sarma D and Hazarika M: Cardiovascular risk factors in children and adolescents with subclinical hypothyroidism. Indian J Endocrinol Metab 21: 823-829, 2017.

18. Lee MK, Kim YM, Sohn SY, Lee JH, Won YJ and Kim SH: Evaluation of the relationship of subclinical hypothyroidism with metabolic syndrome and its components in adolescents: A population-based study. Endocrine 65: 608-615, 2019.

19. Dahl M, Ohrt JD, Fonvig CE, Kloppenborg JT, Pedersen O, Hansen T and Holm JC: Subclinical hypothyroidism in Danish lean and obese children and adolescents. J Clin Res Pediatr Endocrinol 9: 8-16, 2017.

20. Shaoba A, Basu S, Mantis S and Minutti C: Serum thyroid-stimulating hormone levels and body mass index percentiles in children with primary hypothyroidism on levothyroxine replacement. J Clin Res Pediatr Endocrinol 9: 337-343, 2017.

21. Hassapidou M, Fotiadou E, Maglara E and Papadopoulou SK Energy intake, diet composition, energy expenditure, and body fatness of adolescents in northern Greece. Obesity (Silver Spring) 14: 855-862, 2006.

22. Ochoa-Avilés A, Verstraeten R, Lachat C, Andrade S, Van Camp J, Donoso S and Kolsteren P: Dietary intake practices associated with cardiovascular risk in urban and rural Ecuadorian adolescents: A cross-sectional study. BMC Public Health 14: 939, 2014.

23. Moreno LA, Gottrand F, Huybrechts I, Ruiz JR, González-Gross M and DeHenauw S; HELENA Study Group: Nutrition and lifestyle in European adolescents: The HELENA (healthy lifestyle in Europe by nutrition in adolescence) study. Adv Nutr 5: S615-S623, 2014.

24. Rosi A, Paolella G, Biasini B and Scazzina F; SINU Working Group on Nutritional Surveillance in Adolescents: Dietary habits of adolescents living in North America, Europe or Oceania: A review on fruit, vegetable and legume consumption, sodium intake, and adherence to the Mediterranean diet. Nutr Metab Cardiovasc Dis 29: 544-560, 2019.

25. Gu X and Tucker KL: Dietary quality of the US child and adolescent population: Trends from 1999 to 2012 and associations with the use of federal nutrition assistance programs. Am J Clin Nutr 105: 194-202, 2017.

26. Dong H, Yan Y, Liu J, Zhao X, Cheng H, Hou D, Huang G, Li S, Wang Y and Mi J: Alarming trends in ideal cardiovascular health among children and adolescents in Beijing, China, 2004 to 2014. Int J Cardiol 231: 264-270, 2017.

27. Hager ER, Cockerham A, O'Reilly N, Harrington D, Harding J, Hurley KM and Black MM: Food swamps and food deserts in Baltimore City, MD, USA: Associations with dietary behaviours among urban adolescent girls. Public Health Nutr 20: 2598-2607, 2017.

28. Guzzetti C, Ibba A, Casula L, Pilia S, Casano S and Loche S: Cardiovascular risk factors in children and adolescents with obesity: Sex-related differences and effect of puberty. Front Endocrinol (Lausanne) 10: 591, 2019.

29. Doom JR, Mason SM, Suglia SF and Clark CJ: Pathways between childhood/adolescent adversity, adolescent socioeconomic status, and long/term cardiovascular disease risk in young adulthood. Soc Sci Med 188: 166-175, 2017.

30. Karlsen S, Morris S, Kinra S, Vallejo-Torres L and Viner RM: Ethnic variations in overweight and obesity among children over time: Findings from analyses of the health surveys for England 1998-2009. Pediatr Obes 9: 186-196, 2014.

31. Poll FA, Miraglia F, D'avila HF, Reuter CP and Mello ED: Impact of intervention on nutritional status, consumption of processed foods, and quality of life of adolescents with excess weight J Pediatr (Rio J), Aug 1, 2019 (Epub ahead of print). doi: 10.1016/j. jped.2019.05.007.

32. Psaltopoulou T, Tzanninis S, Ntanasis-Stathopoulos I, Panotopoulos G, Kostopoulou M, Tzanninis IG, Tsagianni A and Sergentanis TN: Prevention and treatment of childhood and adolescent obesity: A systematic review of meta-analyses. World J Pediatr 15: 350-381, 2019.

33. Swan GE, Powell NA, Knowles BL, Bush MT and Levy LB: A definition of free sugars for the UK. Public Health Nutr 21: $1636-1638,2018$ 
34. American Diabetes Association: 5. Lifestyle management: Standards of medical care in diabetes-2019. Diabetes Care 42 (Suppl 1): S46-S60, 2019.

35. Sondike SB, Copperman N and Jacobson MS: Effects of a low-carbohydrate diet on weight loss and cardiovascular risk factor in overweight adolescents. J Pediatr 142: 253-258, 2003.

36. Bailes JR, Strow MT, Werthammer J, McGinnis RA and Elitsur Y: Effect of low-carbohydrate, unlimited calorie diet on the treatment of childhood obesity: A prospective controlled study. Metab Syndr Relat Disord 1: 221-225, 2003.

37. Krebs NF, Gao D, Gralla J, Collins JS and Johnson SL: Efficacy and safety of a high protein, low carbohydrate diet for weight loss in severely obese adolescents. J Pediatr 157: 252-258, 2010.

38. Demol S, Yackobovitch-Gavan M, Shalitin S, Nagelberg N, Gillon-Keren M and Phillip M: Low-carbohydrate (low \& high-fat) versus high-carbohydrate low-fat diets in the treatment of obesity in adolescents. Acta Paediatr 98: 346-351, 2009.

39. Institute of Medicine: Dietary reference intakes for energy, carbohydrate, fiber, fat, fatty acids, cholesterol, protein, and amino acids. The National Academies Press, Washington, DC 2005. https://doi.org/10.17226/10490.

40. Duckworth LC, Gately PJ, Radley D, Cooke CB, King RF and Hill AJ: RCT of a high-protein diet on hunger motivation and weight-loss in obese children: An extension and replication. Obesity (Silver Spring) 17: 1808-1810, 2009.

41. Gately PJ, King NA, Greatwood HC, Humphrey LC, Radley D, Cooke CB and Hill AJ: Does a high-protein diet improve weight loss in overweight and obese children? Obesity (Silver Spring) 15 : $1527-1534,2007$
42. Falbe J, Thompson HR, Patel A and Madsen KA: Potentially addictive properties of sugar-sweetened beverages among adolescents. Appetite 133: 130-137, 2019.

43. Bravata DM, Sanders L, Huang J, Krumholz HM, Olkin I, Gardner CD and Bravata DM: Efficacy and safety of low-carbohydrate diets: A systematic review. JAMA 289: 1837-1850, 2003.

44. Smart CE, Annan F, Higgins LA, Jelleryd E, Lopez M and Acerini CL: ISPAD clinical practice consensus guidelines 2018: Nutritional management in children and adolescents with diabetes. Pediatr Diabetes 19 (Suppl 27): S136-S154, 2018.

45. Tallian KB, Nahata MC and Tsao CY: Role of the ketogenic diet in children with intractable seizures. Ann Pharmacother 32: 349-361, 1998.

46. Sothern MS, Despinasse B, Brown R, Suskind RM, Udall JN Jr and Blecker U: Lipid profiles of obese children and adolescents before and after significant weight loss: Differences according to sex. South Med J 93: 278-282, 2000.

47. Couch SC, Saelens BE, Levin L, Dart K, Falciglia G and Daniels SR: The efficacy of a clinic-based behavioral nutrition intervention emphasizing a DASH-type diet for adolescents with elevated blood pressure. J Pediatr 152: 494-501, 2008.

48. Licenziati MR, Valerio G, Vetrani I, De Maria G, Liotta F and Radetti G: Altered thyroid function and structure in children and adolescents who are overweight and obese: Reversal after weight loss. J Clin Endocrinol Metab 104: 2757-2765, 2019. 